\section{More trouble for high fliers}

\section{Washington}

THE temporary disablement of two space shuttles by leaks in the hydrogen feeder lines between the external tank and the orbiter is almost certain to bring extra delays to one or more long-planned astronomy missions, adding to the pain caused by the revelations of manufacturing flaws in the Hubble Space Telescope (see Nature 346, 3; 1990).

Astro-1, an ultraviolet and X-ray astronomy package (see Nature 345, 375; 1990), is waiting for space shuttle Columbia to be repaired after a hydrogen leak was detected shortly before launch. The Gamma-Ray Observatory (GRO) is supposed to fly on shuttle Atlantis in early November, but Atlantis is now stranded on the launch pad at the Kennedy Space Center, Florida. In the meantime the joint US-European solar probe Ulysses must be launched by Discovery in October so that Jupiter is in the right place to give it a gravity-assist into a polar orbit around the Sun. Even if Colmubia or Atlantis were fixed in the next few weeks, the chances are high that Astro-1 or GRO would have to be postponed to let Ulysses fly on time.

The leak in Atlantis was discovered after NASA (National Aeronautics and Space Administration) mission controllers decided, in the light of their experience with Columbia, to conduct a pre-launch 'tanking test' in which the external tank was filled with hydrogen as it would normally be just before launch. They detected a small hydrogen leak, and postponed the Atlantis flight while it and Columbia were investigated. By this time, the various 'umbilical' pipes connecting Columbia to its external tank had been taken apart and tested individually, but the leak could not be reproduced.

Last weekend, NASA engineers tested Columbia's reassembled umbilical system at the Rockwell Downey company, near Los Angeles, where they were built.

This week, Atlantis was being prepared for a new launch-pad test, in which various parts of the umbilical will be surrounded by sealed bags in order to determine which part of the assembly is leaking.

How the launch schedule will be put back together depends on the amount of work needed to fix the leaky sections. If repairs can be made on the launch pad, Atlantis and its secret payload would be sent off as soon as possible, which would probably delay the launch of Astro-1 until after Ulysses. If Atlantis has to be rolled back off the launch pad to be repaired, Columbia and Astro-1 could be launched instead, but then GRO could not be launched until Atlantis's Defense mission had been completed.

David Lindley

\title{
Bargain hunters' paradise in California
}

\section{Washington}

LAWRENCE Livermore Laboratory may be one of the largest US nuclear weapons research and development laboratories, with a strong reputation for its 'Star Wars' research, but it sounds a lot more like the thieves' bazaar of old Baghdad in the just published report of an investigation by the General Accounting Office (GAO).

The report says that equipment worth more than $\$ 45$ million has vanished from the laboratory, which is managed by the University of California, including 49 microcomputers, 205 typewriters and word processors, 841 pieces of video equipment, 388 cameras and related equipment and thousands of calculators. Where has everything gone? A statement put out last week by the office of congressional strong man John Dingell, chairman of the House of Representatives Energy and Commerce Committee and its oversight and investigations subcommittee, noted that allegations had been made at a congressional hearing that "laboratory equipment, such as computers, was stolen and traded for drugs". Dingell, who ordered the GAO investigation, claims that at the laboratory "[w]e have seen drug use, cover-ups, retaliation against concerned employees, poor safety and poor security".

The Department of Energy (DoE) disagrees. In a reply, DoE diplomatically thanks Dingell for his interest, saying in a statement from its San Francisco office that it "consider[s] the findings helpful to improve property management at the lab" and that "improvements are under way". But it also says the laboratory has already located 98 per cent of the 'missing' property. According to DoE spokeswoman Caroline Powell, the San Francisco office has checked that the property is really in place. She says of the GAO failure to find many items, "maybe the thing was in a desk draw and they didn't ask the person who was responsible".

GAO has yet to report on a separate investigation into whether any nuclear materials or classified documents are missing from the laboratory. Dingell has promised to hold hearings later this year to examine the report and DoE's claims.

Alun Anderson EUROPEAN SCIENCE

\section{New Framework row}

\section{London}

Plans by European Community (EC) research commissioner, Filippo Pandolfi, to concentrate EC basic science spending almost entirely on postdoctoral fellowships have set him at odds with member states' representatives on CREST, the EC's scientific and technical research advisory committee. The disagreement could delay spending on basic science through the Framework programme, which supports all research and development efforts in the EC.

EC funds for basic science are set to increase under the third Framework programme, which will run from 1990 to 1994. The increase itself has caused apprehension in some members of the UK research councils, who fear that UK spending through the EC will be taken from the domestic British science budget (see Nature 345, 376; 31 May 1990). But Pandolfi's decision to initiate a 'human capital and mobility' programme which would support several thousand postdoctoral positions has attracted wider opposition.

Only Italy, the present incumbent of the EC presidency and anxious to avoid rifts, has so far not come out against Pandolfi's plan.

Pandolfi argues that promoting the exchange of young scientists between EC member states is useful because it is not strongly supported by individual states. But CREST is concerned that there simply will not be enough young scientists to fill the places, and in any case wants a more diverse programme, with support for postgraduate scientists and large research institutes.

Although the proposed 518 million ECU $(1 \mathrm{ECU}=£ 0.70)$ human capital and mobility programme may include some support for applied science, it is envisaged that it will largely take over from Framework's SCIENCE programme, which is now the centrepiece of EC basic research support.

Supporters of the present diversified system point to the continued success of the SCIENCE programme's research projects, particularly the huge collaborative project on $\mathrm{NdFeB}$ alloy-based magnets (see Nature 338, 734; 1989), which has given Europe the lead in this area. These large-scale projects do, in any case, support a number of postdoctoral researchers.

The current SCIENCE programme is due to end in 1992, but Pandolfi says he plans to fund a continued programme up to 1994 . This will depend on additional money becoming available, however. Sir Peter Swinnerton-Dyer, chairman of the committee that allocates funds under the existing SCIENCE programme, is concerned that there could be a delay in getting the new programme under way, if CREST and Pandolfi cannot quickly reach a compromise.

Peter Aldhous 